\title{
O Duplo Estatuto do SiLÊNCIO ${ }^{1}$
}

\author{
Juliana Hernandez ${ }^{2}$ \\ Instituto de Psicologia - USP
}

\begin{abstract}
Este artigo enfoca a noção de silêncio sob a ótica da psicanálise. Diversas são as referências que nos levam à constatação de que há um duplo estatuto do silêncio - o atendimento clínico, as formulações da psicanálise lacaniana, a literatura de Clarice Lispector. Buscamos conceituar essa duplicidade, articulando um silêncio à noção de vazio e, outro, à noção de falta. Para tal diferenciação, usamos como recursos as noções matemáticas de zero e -1 (subtração de 1).
\end{abstract}

Descritores: Psicanálise. Lacan, Jacques, 1901-1981. Linguagem. Silêncio.

\begin{abstract}
inquietante construção de uma analisante, sobre o silêncio, levourme a percorrer diversos ditos, nos campos mais variados da cultura, acerca do silêncio. Essa interrogação clínica, conto-lhes brevemente.

Essa mulher de meia idade tentara se matar. Socorrida a tempo, sobrevive. Depois disso fora encaminhada para análise, seguida até os dias de hoje. Quisera morrer porque escutava vozes, queria fazê-las calar, não agüentava mais. Precisava de um pouco de silêncio - ele a apaziguava.

Consegue retomar seu trabalho, trabalho este bastante exigente, sustenta fazer análise e segue falando, falando, falando. Até que um dia revela que é insuportável quando um silêncio se instala, por exemplo, na sessão e

1 Este texto faz parte do Projeto de Pesquisa de Mestrado da autora, desenvolvido no Laboratório de Psicanálise Jacques Lacan.

2 Psicanalista, Mestranda em Psicologia Clínica pelo Instituto de Psicologia da USP. Endereço eletrônico: ju.hernandez@bol.com.br
\end{abstract}


que, então, ela precisava falar. Constata que, na verdade, o mesmo acontece em todos os seus encontros com o outro - desespera-se quando a conversa cessa, quando se faz pausa. O silêncio é quase insuportável - ele a atordoa.

Essa aparente discrepância me fisga. Será que essa pessoa se refere à mesma coisa? Trata-se do mesmo silêncio? Um silêncio que apazigua e que atordoa?

O paradoxo clínico, em meu percurso de estudo, primeiro, encontrou eco em duas passagens de Lacan que apresentavam uma bipolarização de sentidos para o silêncio.

Em "Observação sobre o relatório de Daniel Lagache: Psicanálise e estrutura da personalidade", Lacan (1960/1998) fala de uma ética convertida ao silêncio e, ao fazê-lo, nos apresenta o que seria uma dupla alternativa de silêncio: uma pela via do pavor e outra pela via do desejo. Ele assim diz: "Uma ética se anuncia, convertida ao silêncio, não pelo caminho do pavor, mas do desejo: e a questão é saber como a via de conversa da experiência analítica conduz a ela" (p. 691).

Santiago (1996) comenta essa distinção entre dois tipos de silêncio, empreendida nesse texto por Lacan. Considera que a via do silêncio do pavor não é a via da psicanálise e comenta, ainda, que essa frase oferece mais uma indicação, a saber, a de que a passagem da via de conversa (que ela traduz por tagarelice) para o silêncio é algo produzido na análise.

Sete anos mais tarde, Lacan (1967/s.d.), no Seminário A Lógica do Fantasma, sustentou o uso de dois nomes diferentes para designar o silêncio: sileo e taceo. Taceo seria o da palavra não-dita, do calar, do silenciar ou ser silenciado. De outra parte, sileo seria um silêncio fundante, estruturante, sugestivo da ausência essencial da palavra, do buraco da significação. Nas suas palavras: “(...) sileo não é taceo. O ato de calar-se não libera o sujeito da linguagem apesar de que a essência do sujeito culmine nesse ato..." (Lacan, 1967/ s.d.).

A partir daí, iniciei uma busca, de certa maneira informal, por alguns campos da cultura que tomaram o silêncio como objeto de reflexão e estudo. Primeiro, ainda sem contornos de uma pesquisa, mergulhei na literatura de 
Clarice Lispector (1998), da qual tirei algumas boas e poéticas contribuições. Depois fui ver o que a lingüística tinha a dizer sobre esse assunto e então encontrei a obra da lingüista Eni Orlandi (1997), que também me deu um tanto de boas pistas para entender um pouco melhor de que se trata o silêncio. Esbarrei na filosofia de Badiou (1994a, 1994b) e suas construções matemáticas sobre o inominável, espécie de silêncio.

\section{O silêncio na Literatura de Lispector}

No campo das artes, o silêncio despertou interesse - de poetas, escritores, teóricos literários, artistas, músicos. O que eles puderam formular, conceber, acerca do silêncio a partir de seus olhares específicos? Que pistas nos fornecem?

Pode soar estranho que se comece pela literatura de Clarice Lispector. Mas essa escolha tem uma história pessoal e, sobretudo, um fundamento que, poderíamos dizer, teórico, na falta de uma definição melhor. Waldman (1998, p. 285), estudiosa da obra de Clarice, considera o silêncio um operador lógico da obra dela:

O silêncio, na obra de C. L., é tanto um tema com o qual seus personagens estão sempre às voltas, como uma atmosfera que marca o espaço interno dessas mesmas personagens, como também algo que está no horizonte do processo de criação da autora...

Há uma concepção específica, um lugar singular para o silêncio nos seus escritos de forma geral e, em alguns escritos em particular, o que faz de Lispector uma referência importante, advinda do campo literário, para o estudo do silêncio.

De acordo com Waldman (1998), o silêncio estaria na obra de Clarice Lispector como ponto central em torno do qual as histórias, as palavras, as personagens girariam, sem, no entanto, chegar nunca a tocá-lo, o que a leva a concluir que há "uma tentativa sempre frustrada de capturar algo que ainda 
não foi dito", mas que, paradoxalmente, permite inúmeros ditos - seus diversos textos.

Do ponto de vista da psicanálise, poderíamos dizer que a estrutura linguageira permite muitos ditos, ao mesmo tempo que está fundamentada na impossibilidade estrutural de tudo-dizer. A fantasia (imaginário) se articula por meio dessa estrutura linguageira para encobrir um silêncio/real, sem, no entanto, poder jamais chegar a tocá-lo.

Clarice Lispector (1998), em um de seus contos do livro Onde Estivestes de Noite, intitulado justamente "Silêncio", pode nos aproximar dessa retórica. É como se esse texto tivesse me escolhido e não eu a ele, há muito tempo, o que já justifica ter sido ele o escolhido, apesar de a temática se fazer presente em tantos outros:

... Como estar ao alcance dessa profunda meditação do silêncio. Desse silêncio sem lembrança de palavras. Se és morte, como te alcançar.

É um silêncio que não dorme: é insone: imóvel mas insone; e sem fantasmas. É terrível - sem nenhum fantasma. Inútil querer povoá-lo com a possibilidade de uma porta que se abra rangendo, de uma cortina que se abra e diga alguma coisa. Ele é vazio e sem promessa. Se ao menos houvesse o vento. Vento é ira, ira é vida. Ou neve, que é muda, mas deixa rastro - tudo embranquece, as crianças riem, os passos rangem e marcam. Há uma continuidade que é a vida. Mas este silêncio não deixa provas. Não se pode falar do silêncio como se fala da neve. (Clarice Lispector, 1998)

Diz Clarice Lispector haver um silêncio "sem lembrança de palavras", "que não dorme: é insone: imóvel mas insone", e que não está no campo do registro imaginário: "é um silêncio sem fantasmas". Ela explica: "ele é vazio e sem promessa"; "é inútil esquivar-se: há o silêncio". Ela continua:

Entra-se nele [no silêncio], vai-se com ele (...) Será como se estivéssemos num navio tão descomunalmente enorme que ignorássemos estar num navio. E es te singrasse tão largamente que ignorássemos estar indo. Mais do que isso um homem não pode. Viver na orla da morte e das estrelas é vibração mais tensa do que as veias podem suportar. (Clarice Lispector, 1998) 
Desta forma, conta-nos que entrar em contato com ele é possível apenas com certa distância e precaução, havendo risco de morte se assim não o for. Perante esse silêncio nos resta o assujeitamento, a alienação: "quando este se apresenta todo nu, nem é comunicação, é submissão. Pois nós não fomos feitos senão para o pequeno silêncio".

Subentende-se que aquele silêncio, outro, se faz grande, talvez absoluto. Só ao pequeno poderíamos aceder.

A saída possível (como também atesta a psicanálise) se faz com a entrada de um terceiro elemento: "Que se espere. Não o fim do silêncio mas o auxílio bendito de um terceiro elemento, a luz da aurora".

Freud, e depois Lacan, apontaram como, na constituição do sujeito, é preciso que haja um corte na relação mãe-bebê para que este se perceba diferente dela, ou seja, outro. A saída da completude mãe-bebê, completude que se instala como gozo, se faz pela via de um corte, da entrada de um terceiro, o pai, na configuração edípica.

Clarice Lispector aponta, então, que dessa operação resta algo, algo nas entrelinhas: resto de silêncio, apagado como experiência absoluta, mas passível de encontros parciais. Diz:

Depois nunca mais se esquece. Inútil até fugir para outra cidade. Pois quando menos se espera pode-se reconhecê-lo - de repente. Ao atravessar a rua no meio das buzinas dos carros. Entre uma gargalhada fantasmagórica e outra. Depois de uma palavra dita. Às vezes no próprio coração da palavra. Os ouvidos se assombram, o olhar se esgazeia - ei-lo. E dessa vez ele é fantasma.

No mínimo Clarice fala aqui de dois silêncios, qual seja, de um que é vazio, diante do qual nos assujeitamos sem escolha, e de um outro que ela diz "pequeno silêncio", no meio do conto e, ao final, fantasma. Um silênciofantasma, possível pelo corte da luz da aurora no silêncio-vazio, retorna à revelia das fugas - "inútil fugir" - para velar, ao mesmo tempo que revelar, esse silêncio-vazio.

Estaria minha analisante denunciando essas diferenças? 


\section{O silêncio na Lingüística}

Dentro do campo da Lingüística e da Análise do Discurso alguns autores abordaram, por diferentes focos, esse assunto. É bem verdade que, ao contrário do se poderia supor, Linguíística e Psicanálise não são áreas próximas ou facilmente aproximáveis.

Kristeva e Rudelic-Fernandez (1996, p. 661), no Dicionário Enciclopédico de Psicanálise - O Legado de Freud e Lacan, abordam a relação entre psicanálise e lingüística e afirmam haver historicamente uma "incompatibilidade" entre ambas devida a "concepções radicalmente diferentes do sujeito e da linguagem", apesar de concordarem que algumas poucas tentativas nesse sentido foram felizes.

Ousarei alguma aproximação entre o silêncio da psicanálise e o silêncio da lingüística, buscando, entretanto, cuidar dos riscos de importação de conceitos de uma área à outra. Baremblitt (1992, p. 10) dizia:

As idéias, como a terra, são de quem as trabalha. Freud costuma dizer que é perigoso transplantar os conceitos para longe do seu chão nativo, mas cabe acrescentar que quando tal coisa acontece, e eles sobrevivem, novas espécies maravilhosas nascem.

No que se refere ao tema do silêncio propriamente dito, a versão linguística mais corrente foi pensá-lo como implícito e como elipse.

Nessa conceituação, de qual silêncio se trata? O silêncio é aquilo que, não dito, poderia ter sido, ou seja, é um silêncio que encontra correspondência na palavra, é passível de se tornar dito, é enunciável.

Orlandi (1997, p. 68) discorda dessa definição para o silêncio que é feita de forma "relativa-negativa", mantendo uma relação ancilar ao dizer, na qual se traduz o não-dito em dito. Ela apresenta uma concepção diferente para o silêncio no campo da lingüística. Na sua opinião, o silêncio tem sido relegado ao que chamou de "uma posição secundária como excrescência, como o "resto" da linguagem" (p. 12). Sua proposta é abordá-lo como figura 
e não como fundo, para usar sua expressão. Tomá-lo pelo que ele é, e não pelo que não é.

Para essa autora, a relação entre linguagem e silêncio precisa ser abordada e, no seu livro As Formas do Silêncio (Orlandi, 1997, p. 23), estabelece-a de duas formas. Primeiramente, defende que o silêncio deve ser tomado como mais do que um complemento da linguagem, argumentando que ele tem um "caráter necessário e próprio". Isso não quer dizer que ele tenha um sentido independente, pré-existente, absoluto, nem que tenha sentidos metafóricos, traduzíveis em palavras. Tampouco sugere que o sentido do silêncio seja encontrado na intenção do locutor.

Quer tão somente dizer que ele tem a função de garantia do movime nto dos sentidos. Sendo assim, nesse primeiro estágio, o silêncio não se configura como uma alteridade em relação à linguagem, ou seja, não está fora da linguagem, e, entretanto, não é só um complemento dela. Tampouco constitui-se como o abismo dos sentidos, mas sim, como o possibilitador de efeitos de sentido, o que põe em jogo os processos de significação.

Ele é o ponto de sustentação para o que Orlandi chamou de "não-um" (ou seja, os muitos sentidos, a polissemia), e, ao mesmo tempo, da possibilidade do "efeito do um" (ou seja, do sentido literal).

Em um segundo momento de seu livro, aponta que o silêncio é exterior à linguagem, anterior a ela, configurando-se em um estado primeiro em torno do qual a palavra se movimenta (Orlandi, 1997, p. 32). Nesse sentido, ele é tomado como a marca, na linguagem, da incompletude.

... a incompletude é fundamental no dizer. É a incompletude que produz a possibilidade do múltiplo, base da polissemia. E é o silêncio que preside essa possibilidade. A linguagem empurra o que ela não é para o "nada". Mas o silêncio significa esse "nada" se multiplicando em sentidos: quanto mais falta, mais silêncio se instala, mais possibilidade de sentidos se apresenta. (p. 49)

Segundo Orlandi, a incompletude é própria a todo e qualquer processo discursivo. Ela assim define a função do silêncio na constituição do sujeito e na constituição do sentido: 


\title{
Juliana Hernandez
}

\begin{abstract}
a) o silêncio, na constituição do sujeito, rompe com a absolutização narcísica do eu que, esta, seria a asfixia do sujeito já que o apagamento é necessário para sua constituição: o silenciamento é parte da experiência da identidade, pois é parte constitutiva do processo de identificação, é o que lhe dá espaço diferencial, condição de movimento; b) o silêncio, na constituição do sentido, é que impede o non sense pelo muito cheio, produzindo o espaço em que se move a materialidade significante (o não-dito necessário para o dito). (p. 51)
\end{abstract}

De forma resumida, essa autora concebe o silêncio com dupla forma: há um silêncio que chama de fundador, e outro, o das diversas formas de silenciamento, que ela chama de política do silêncio.

O silêncio fundador é aquele que nos indica que "(...) todo processo de significação traz uma relação necessária ao silêncio” (Orlandi, 1997, p. 55).

O silêncio da política do silenciamento, ela o divide em dois - constitutivo e local. O constitutivo é o que nos indica que, para dizer, é preciso não-dizer, já que uma palavra apaga necessariamente as outras. Já o local refere-se à censura, ao proibido de se dizer em determinada conjuntura.

Orlandi está propondo uma outra forma de silêncio, fundador, que tem lugar como um operador lógico que permite que haja a própria possibilidade de significar. Do ponto de vista da psicanálise, poderíamos entender que está falando de um silêncio que está na cadeia significante, nos seus intervalos, e um silêncio que marca a incompletude do Outro.

\section{O silêncio Primordial de Kovadloff}

Há um ensaísta, Kovadloff (2003), que escreveu um livro com uma série de artigos sobre o silêncio, cuja concepção novamente nos lança no campo de uma dualidade. Ele se interessa por uma modalidade de silêncio que nomeia primordial e demarca a diferença entre esse silêncio e outro. Com isso, reconhece que haja mais de um silêncio, apesar de seu trabalho incidir somente sobre um deles.

O semblante explicável do silêncio não me interessa. (...) Não desejo falar do que, silenciado, poderia ser dito alguma vez. (...) Quero, em vez disso, falar do silêncio 
que não cumpre a função de maquiagem e que, como tal, não encontra nem pode encontrar equivalência na palavra. Quero, em suma, falar de um fundo irredutível. (Kovadloff, 2003, p. 9)

Para esse autor há um silêncio insuperável, ausência originária, silêncio absoluto, ao qual só se tem acesso em termos de semblante. Chama-o de primordial. Há, de outra parte, um silêncio imposto pela palavra não-dita, o silenciado que, como tal, é passível de enunciação.

\section{O silêncio na sua relação com a verdade e o saber}

Na década de setenta, Lacan trabalhou as noções de saber e verdade e afirmou que a verdade não pode ser dita toda, somente ser semi-dita. Há algo irremediavelmente barrado ao dizer, silêncio, no que se refere à verdade. Muitos dedicaram-se a trabalhar tais idéias. No contexto dessa pesquisa, localizar que algo não pode ser dito nos sinaliza um campo do silêncio.

Badiou (1994b, p. 9), filósofo que se dedica, nas suas palavras, "tanto quanto possível, à psicanálise renovada por Lacan, aos desdobramentos da matemática fundamental (conjuntos e categorias), ao balanço das políticas de emancipação no século, à literatura, à poesia etc", no texto $A$ verdade e $O$ Inominável, apresenta, com esse repertório, uma teoria que permite identificar duas possibilidades de silêncio.

Badiou mostra, fazendo uso de um aporte da matemática, a existência de verdades que não podem ser reduzidas ao saber, a inexistência de predicados na língua, por mais sofisticados que sejam, que dêem conta da verdade. Entretanto, também demonstra que, apesar disso, existe uma fórmula de lidar com a verdade que adviria do "método do forçamento".

... uma verdade, por mais inacabada que seja, autoriza antecipações de saber não sobre o que é, mas sobre o que terá sido se a verdade chegar a seu acabamento. (...) daquilo que é uma verdade quase nada se pode dizer. Mas daquilo que acontece sob a condição que ela terá sido existe um forçamento em que quase tudo se pode enunciar (...) Impotente para ser dita toda, uma verdade é, no entanto, capaz de forçar saberes. (Badiou, 1994b, p. 68) 
Temos assim apresentada uma visão de que um silêncio pode tornarse dito e, nesse caso, o silêncio pode ser nomeado como não dito. Porém, Badiou avança e apresenta uma outra forma de silêncio, diferente desta. De seu "método" diz que existe sempre "um ponto de tropeço absoluto", inforçável. Ele o chama de inominável. E afirma ser esse o "real da verdade", "um grão de real que emperra a máquina da verdade".

Um real é o encontro de um termo, de um ponto, um só em que a potência da verdade se interrompe. Um termo do qual nenhuma suposição antecipante permite forçar o julgamento. Um termo propriamente inforçável (Badiou, 1994b, p. 71).

Desta forma, Badiou apresenta a idéia de que há um não-dito, incapaz de tornar-se dito. Um ponto de silêncio absoluto, sem possibilidade de palavras. Silêncios passíveis de serem enunciados, cabíveis em predicados da língua, em palavras, "forçados" e o silêncio, o indizível, o inominável, inforçável. Mais uma vez, dois terrenos distintos para o silêncio são demarcados: o passível de ser dito (dizível) e o inominável.

\section{O Silêncio na Religião}

Em 1771, inspirado pela pergunta quem dará a arte de calar?, feita pelo cardeal Le Camus ao padre Lamy de l'Oratoire, o abade Dinouart lança-se na tarefa de estabelecer os elementos da arte de calar, “... explicar seus princípios e sua prática” (Dinouart, 2001, p. 9), segundo suas palavras.

Já na introdução, Dinouart alerta que falará do silêncio em contraponto à palavra, já que considera ser preciso, para explicar um objeto, elucidar tantos outros com os quais mantém relação essencial.

Quando se trata de circunscrever um objeto, delimitar-lhe o campo, é tarefa natural, dentro do âmbito das ciências, estabelecer relações de oposição, uma vez que, ao definir opostos, marca-se um contorno para um objeto. Isso parece ser mais relevante quando se trata de um objeto de estudo tão fugaz e pouco palpável quanto o silêncio. É de acordo com tais idéias que 
Dinouart (2001) encaminha sua arte de calar. Ele assim se expressa: “(...) não se pode falar das trevas sem o conhecimento da luz, nem do repouso sem referência ao movimento. Ao tratar do silêncio, portanto, farei freqüentemente reflexões sobre a palavra (...)" (p. 10).

Compartilho da necessidade de abordar opostos no trajeto de delimitação de um objeto, entretanto, busco estabelecer parâmetros positivos na definição do silêncio, ou seja, demarcar o que ele é, isso sob a ótica da psicanálise, sem excluir da pesquisa a demarcação de fronteiras e oposições.

O próprio abade Dinouart faz esforços nesse sentido quando se propõe a definir os "princípios necessários para calar" e as diferentes espécies de silêncio. Os apresentadores de seu texto, Courtine e Haroche dirão que sua tipologia constitui uma semiótica do silêncio. Parece mais uma descrição fenomenológica de diversos tipos de silêncio: prudente, artificioso, complacente, zombador, espirituoso, estúpido, de aprovação, de desprezo, de humor, de capricho e político.

Dos princípios que arrola, faz uma apologia ao silêncio, afirmando que ele é um lugar seguro, no qual não haveria "excessos a temer" (Dinouart, 2001, p. 13). Isso se coloca porque, para Dinouart, o silêncio conserva o homem de forma mais completa e plena. Ele assim escreve: "O homem nunca é tão dono de si mesmo quanto no silêncio: fora dele, parece derramar-se pelo discurso; de modo que ele pertence menos a si mesmo do que aos outros" (p. 12).

$\mathrm{O}$ ato de Dinouart de escrever A Arte de Calar pode ser considerado político na medida que pretende, enaltecendo o silêncio, defender a Igreja dos progressivos "falatórios" filosóficos. Courtine e Haroche assim o afirmam:

É preciso defender a Igreja e reduzir ao silêncio aqueles que a atacam. (Dinouart, 2001, p. xiv)

O tema religioso do silêncio, a serviço da razão de estado, funda uma pedagogia da contenção, uma disciplina da reserva, uma arte da reticência. (p. xviii) 
A concepção de silêncio de Dinouart consiste em uma defesa frente à perdição, à despossessão, e, enquanto tal, uma virtude a ser valorizada. Segundo os apresentadores de seu texto, para Dinouart, a linguagem é um "lugar de excessos" no qual o sujeito pode facilmente se perder de si, “... ele corre o perigo de ser mais dos outros do que de si mesmo" (2001, p. xxiii).

Idéia discutível, uma vez que o homem constitui-se como tal pela linguagem, porém, interessante, na medida em que evoca de saída os dois mecanismos constitutivos do sujeito propostos por Lacan - a alienação e a separação. Nesse caso, a condição da separação estaria no silêncio e a da alienação na linguagem.

É verdade que o tema do silêncio continuou a ser privilegiado dentre os temas religiosos. Os votos de silêncio, o silêncio de Deus ou o silêncio diante de Deus. Alguns pensadores, mesmo que não religiosos, interessaram-se por aprofundar-se no tema.

Kovadloff (2003), ensaísta, poeta e tradutor da língua portuguesa, propôs-se a pensar o silêncio em diversos âmbitos da cultura e um deles foi no religioso. Interessou-se pelo silêncio monástico. $\mathrm{O}$ autor aponta duas modalidades de silêncio em referência a Deus: silêncio de Deus e silêncio diante de Deus.

Diferentemente de Dinouart, que pregava o silêncio com o argumento de que nele o homem está mais próximo de si, resguardando mais a sua essência, Kovadloff mostra-nos que o silêncio monástico implica o reconhecimento da insignificância pessoal e permite a transcendência.

Orlandi, autora proveniente de uma outra abordagem, a da linguística, também na elaboração de sua concepção do silêncio, esbarrou no discurso religioso, mesmo que de forma breve, tal é a pertinência desse campo para o tema. Para ela o que funciona na religião é a onipotência do silêncio Divino: "Deus é o lugar da onipotência do silêncio" (Orlandi, 1997, p. 30). Orlandi reafirma que, historicamente, o silêncio esteve ligado ao sagrado, às religiões. Cita Pitágoras, que exigia de um a três anos de silêncio para iniciação na ordem religiosa; cita Sócrates, que referendava um lugar de importância para o silêncio como forma de conhecimento. "Os místicos, os cristãos, os 
neoplatônicos, os persas, os hindus, os árabes, os judeus na Idade Média, fizeram largo uso do silêncio como meio de encontrar Deus" (Olrandi, 1997, p. 64).

Enfim, por diferentes vias: silêncio e religião; silêncio e Deus. Não há dúvida, e as referências acima são apenas indicativas, de que Deus e religião estão, historicamente e também no imaginário popular, relacionados ao silêncio. Orlandi (1997, p. 65) chega a creditar a isso a explicação para a pouca reflexão sobre o silêncio em sua "materialidade significativa". A questão a saber é: de que(ais) silêncio(s) se trata no discurso religioso? Encontramos, por um lado, a idéia de que o silêncio garante aos homens a sua consistência, por permitir a concentração da essência humana e, por outro lado, que ele é o lugar da transcendência maior, ou seja, lugar de um esvaziamento do sujeito para se aproximar de Deus.

\section{Dois Silêncios...}

Há vários ditos diferentes sobre o silêncio e, neles, encontramos uma recorrente suposição de duplicidade de sentidos ou formas de silêncio:

- no recorte clínico, um silêncio que apazigua e um que atordoa;

- no Lacan do Relatório de Daniel Lagache, um silêncio do pavor e outro do desejo;

- no Lacan de 1967, Lógica do Fantasma, silêncio como sileo e silêncio como taceo;

- da literatura de Lispector, tiramos uma idéia de silêncio como vazio e uma outra idéia de que há um silêncio, resto daquele primeiro, apresentado, agora, como fantasma;

- do discurso da lingüística, temos a idéia de um silêncio traduzido como implícito, ou seja, passível de ser enunciado e, por outra parte, temos as formulações de Orlandi que o classifica em duas formas: o silêncio fundador, um silêncio do inominável, mas fundamental para o dizer, e o silêncio das políticas de silenciamento; 
- Kovadloff também fala de um silêncio primordial e de outro que chamou de silenciado;

- nas construções apresentadas por Badiou, há um silêncio não-dito, porém enunciável, e outro inominável;

- do discurso religioso temos a idéia de que o silêncio é o lugar da separação, ou seja, aquele que guarda, da melhor forma, o sujeito em sua essência, ou da alienação, quer dizer, aquele lugar em que o sujeito está menos ali, transcendeu, está no Outro/Deus;

Empreendemos a tentativa de reduzir todas essas formulações a denominadores mínimos, identificar dois significantes que dessem conta de condensar os dois grupos de significantes recolhidos nos vários ditos. Uma modalidade de silêncio poderia ser designada vazio e, a outra, falta. Adiante explicarei passo a passo o que sustenta tal proposição.

O desafio então será enfrentar o problema por uma via segura. Tentemos abordar tal questão, acatando o seguinte conselho lacaniano de usar com rigor o simbólico: “... podemos escrever assim, e fazer funcionar sob sua forma mais estrita, aquilo que, desde a origem de um uso rigoroso do simbólico, se manifesta na tradição grega, a saber, no nível das matemáticas" (Lacan, 1969-1970/1991, p. 147).

Porque Lacan nos ensinou que o uso das matemáticas possibilita “...uma articulação mais segura do que vem a ser o efeito do discurso." (Lacan, 1969-1970/1991, p. 149). A formalização matemática burla os desvios, os mal-entendidos e a dispersão de sentido, próprios ao discurso, garantindo a transmissão.

\section{A matemática do silêncio}

Kovadloff (2003) é um autor não matemático, mas que, entretanto, dedicou-se a pensar qual seria o equivalente, em termos matemáticos, do silêncio que chamou de primordial. A resposta resultante de sua pesquisa foi o número zero. 
O zero, ao que tudo indica, é a expressão matemática do silêncio primordial; a locução matemática que realiza o inexequível. O nada se deixa nomear como zero para que acedamos, dentro do cenário matemático, à eloqüência do silêncio extremo - incógnita insuperável que irrompe em relação, e por oposição, ao cifrado. (p. 98)

A definição matemática do zero se fez questão para muitos matemáticos e filósofos. "Com a incorporação do zero ao território dos grandes dilemas, a matemática alcança, talvez, a sua tensão máxima e o mais profundo lirismo em seu processo de autocompreensão" (Kovadloff, 2003, p. 101).

De acordo com Kovadloff, tratava-se de explicá-lo como um operador lógico. Ainda segundo ele, o que resulta da construção de Russell segundo a qual não há quantidade cuja magnitude seja zero, é que o próprio do número será a cifra e o do zero o indecifrável. E esse indecifrável é o real. "Mesmo que inúmeras vezes se divida o um, ainda assim não se chega ao zero. Mais fácil chegar ao infinito" (Kovadloff, 2003, p. 101). "O infinito é, pois, o porvir do numérico. Zero, por sua vez, não é nem sequer o seu reverso. É sua alteridade radical" (p. 99).

Com isso já fica marcada uma importante distinção na definição do silêncio: ele não é da ordem do infinito, como alguns poderiam supor, mas da ordem do zero. "Zero e infinito não são, portanto, sinônimos. O infinito é o campo inesgotável do matematicamente possível. O zero, por sua vez, é o campo do impossível; o insondável campo do impossível (Kovadloff, 2003, p. 102).

Pensemos, no entanto, do ponto de vista do sujeito, de sua constituição. De um silêncio, do zero, como fazer algo existir, consistir? Como do nada, do vazio, do silêncio, se constrói algo, algo existe?

Badiou (1994a), em um artigo intitulado Um, dois, três, quatro e também zero, dirá que o zero é aquele que não é o Outro de nada, ele é um conjunto vazio e, como tal, é pura letra, marca real. Diz ele:

Nada existe a partir de zero, nada pertence a zero. A isso chamamos de conjunto vazio (...) O vazio não é composto de nada... ele é pois uma pura letra. Dir-se-á que zero é uma marca real (...) Para um psicanalista, o conjunto vazio não é símbolo de nada. É a letra do não simbolizável. Logo, a letra do real. (Badiou, 1994a, p. 96) 
Desta forma, resta a pergunta: como construir algo - o sujeito, o mundo, o sentido - a partir do zero/silêncio?

A matemática nos mostra, novamente, o caminho na passagem do zero ao 1 . Na realidade, Kovadloff afirma que não se trata de passagem do zero ao um, mas de salto. "Não se passa de zero a um; salta-se de zero a um. Salta-se e, então, se começa a enumerar...” (p. 97) Como isso se daria? “O zero é o enigma que envolve essa condição de possibilidade do um; o nada em que se abriga o mistério da origem, e que, como tal, precede o um” (p. 100).

Muitos matemáticos e filósofos esbarraram na questão. Também Badiou (1994a) preocupou-se em determinar a relação entre zero e um. O 1 é o número que indica o conjunto das partes do zero - $1=\mathrm{p}(\varnothing)$. O que isso quer dizer?

O 1 é então o que inscreve que zero existe. Mas o que inscreve que um real existe? É o simbólico como tal. Dir-se-á que 1 é a cifra do simbólico. O 1 é o traço unário, quer dizer, o mínimo de Outro possível para a pura letra do real. (Badiou, 1994a, p. 99)

Assim, no seio do vazio, do nada, do silêncio, é possível encontrarmos alguma positividade, encontrar 1 em zero. O zero é o elemento de um conjunto, conjunto esse grafado como 1 . O ser marcado como $u m$, partindo do zero, consiste na identificação-pivô.

No Seminário 14, A Lógica do Fantasma, em 15/03/1967, Andre Green faz uma apresentação na qual adentra nas relações entre o Um unificante e o zero. Ele diz que o sujeito está sempre capturado entre o zero e o Um, sendo o zero o um-contável, ou seja, o conjunto vazio é escrito com o número 1. Com isso ele estabelece: “... também o zero deve ter um duplo estatuto, quer dizer, que pode ser ou passagem de zero ao um que é produção da cadeia (necessidade do zero para a combinatória), ou bem o zero como desubjetivação radical" (Green, 1967).

Se o zero grafa uma das modalidades do silêncio, como sustentamos até aqui, resta ainda construir uma forma de transmitir numericamente o outro silêncio. Lançarei mão de uma argumentação de Ivan Corrêa, no livro 
A Psicanálise e Seus Paradoxos - Seminários Clínicos, acerca da diferença existente entre o vazio (que ele também define como o zero ou o nada) e a falta (em outros termos, buraco e furo). Diz ele:

... o conjunto vazio é o conjunto que inscreve o nada, a inexistência e não a falta (...) Mas, se não há nada, não há nada. A falta é quando devia haver alguma coisa e não há. Quer dizer é o menos um (-1), não é o zero. (Corrêa, 2001, p. 52)

Desta forma, a falta sempre será relacionada com uma retirada. Primeiro, é preciso que haja a ruptura de uma experiência total (aliás, só perceptível como total uma vez finda, já que um contínuo de nada ou de silêncio não é perceptível), para que a descontinuidade permita o reconhecimento do estado ou condição anterior. É a quebra, a ruptura, o corte, a castração, que permitirá que algo exista: "A descontinuidade cria a borda e a borda cria o ser separado - um buraco, por exemplo" (Corrêa, 2001, p. 54).

Não é de modo algum por acaso que Lacan (1965/s.d.), no Seminário - Problemas Cruciais para a Psicanálise, comenta a questão do silêncio a partir do quadro de Munch, $O$ grito. Ele afirma que é o grito que provoca o silêncio, ao anulá-lo, ele o faz surgir: “...o grito faz o abismo de onde o silêncio se precipita".

Se a definição do zero foi compatível com um dos estatutos do silêncio, conforme afirmado nas páginas anteriores, no seu outro estatuto, o silêncio é compatível com a definição matemática da falta - subtração de 1 (1). Trata-se do silêncio que Lacan nomeou "taceo", daquele da palavra retirada, interrompida, do silêncio dos encontros parciais do conto de Clarice Lispector, de um resto de silêncio, do silêncio da via do desejo de que falava Lacan em “Observação sobre o relatório de Daniel Lagache”. É esse o único que podemos conhecer. O silêncio do nada, do vazio, do zero, é a morte.

Em suma, há um grande número de significantes, de recursos discursivos e recursos matemáticos para tentar dizer bem o silêncio: silêncio do vazio, do nada, do zero, sileo, inominável, inforçável, a morte e, por outra parte, silêncio de taceo, do -1, da palavra não enunciada, do resto. 
Percorrido esse trajeto, voltemos ao caso apresentado no início. O silêncio buscado pela analisante na sua tentativa de suicídio é outro, diferente daquele que ela reclama, anos depois, nos seus encontros com o outro e na análise. Aquele silêncio era um mergulho no vazio; esse um confronto com a falta. Aquele silêncio zerava a existência, esse permite circular seus modos de ser e existir.

Hernandez, J. (2004). The double statute of the silence. Psicologia USP, 15(1/2), 129-147.

\begin{abstract}
This article focus on the notion of silence under the perspective of the psychoanalysis. Several are the references that lead us to verify the double statute of the silence - the clinical "procedure", the "formulations" of the lacanian psychoanalysis, the literature of Clarice Lispector, the linguistic theory of Eni Orlandi. The aim is to judge this duplicity, linking one silence to the notion of emptiness and the other one to the notion of absence. For such differentiation, is used the resource of the mathematical notion of zero and -1 (minus one).
\end{abstract}

Index terms: Psychoanalysis. Lacan, Jacques, 1901-1981. Language. Silence.

Hernandez, J. (2004). Le Double Statut du Silence. Psicologia USP, $15(1 / 2), 129-147$.

Résumé: Cet article traite de la notion du silence dans la perspective de la psychanalyse. Il y a des divers références qui constatent l'existence d'un double statut du silence - la clinique, les formulations de la psychanalyse lacanienne, la littérature de Clarice Lispector. On cherche à expliquer le concept de cette duplicité ajoutant un silence à la notion du vide et un autre à la notion du manque. Pour cette différentiation, on utilise les notions mathématiques de zéro et de -1 (soustraction de 1).

Mots-clés: Psychanalyse. Lacan, Jacques, 1901 -1981. Lingage. Silence. 


\section{Referências}

Badiou, A. (1994a). Um, dois, três, quatro, e também zero. In A. Badiou, Para uma nova teoria do sujeito (pp. 95-105). Rio de Janeiro: Relumé-Dumara.

Badiou, A. (1994b). A verdade e o inominável. In A. Badiou, Para uma nova teoria do sujeito (pp. 65-73). Rio de Janeiro: Relumé-Dumara.

Baremblitt, G. (1992). Cinco lições sobre a transferência. São Paulo: Hucitec.

Corrêa, I. (2001). A psicanálise e seus paradoxos. Seminários clínicos. Recife: Ágalma.

Dinouart, A. (2001). A arte de calar. São Paulo: Martins Fontes.

Kovadloff, S. (2003). O silêncio primordial. Rio de Janeiro: José Olympio.

Kristeva, J., \& Rudelic-Fernandez, D. (1996). Psicanálise \& lingüística. In P. Kaufmann (Ed.), Dicionário enciclopédico de psicanálise:O legado de Freud e Lacan (pp. 661-670). Rio de Janeiro: Jorge Zahar.

Lacan, J. (s.d.). Seminário 12: Problemas cruciales para el psicoanálisis. Mimeografado.

Lacan, J. (1998). Observação sobre o relatório de Daniel Lagache: Psicanálise e estrutura da personalidade. In J. Lacan, Escritos. Rio de Janeiro: Jorge Zahar. (Trabalho original publicado em 1960)

Lacan, J. (s.d.). Seminario 14. La logica del fantasma. Mimeografado. (Trabalho original publicado em 1967)

Lacan, J. (1991). O seminário. Livro 17: O avesso da psicanálise. Rio de Janeiro: Jorge Zahar. Trabalho original publicado em 1969-1970)

Lacan, J. (1975/1976). Scilicet 6/7. Paris: Seuil.

Lispector, C. (1998). Silêncio. In Onde estivestes de noite. Rio de Janeiro: Rocco.

Orlandi, E. P. (1997). As formas do silêncio: No movimento dos sentidos. Campinas, SP: Ed. UNICAMP.

Santiago, A. L. (1996, abril). A ética do silêncio. Curinga: Ressonâncias da Interpretação. Escola Brasileira de Psicanálise, (7), 70-73.

Waldman, B. (1998) A retórica do silêncio em Clarice Lispector. In L. C. U. Junqueira Filho, Silêncios e luzes: Sobre a experiência psíquica do vazio e da forma. São Paulo: Casa do Psicólogo. 